\title{
CMC to support an online learning environment
}

\author{
Dianne P. Chambers \\ The University of Melbourne, Australia
}

\begin{abstract}
Computer mediated communication (CMC) is used in a postgraduate subject that is offered to both online and campus-based students at the University of Melbourne. Data sources are students' emails to the lecturer and postings to the discussion forum by students in this subject (on campus and online students) in 2000 and 2002. Students were directed, but not required, to make postings to the subject's discussion forum and most students used email as the most convenient means of communicating with the lecturer. These data allow a comparison of the use of CMCs by on campus and online students, and a comparison of use in 2000 and 2002. Findings indicate that use of email increased from 2000 to 2002, while postings to the discussion forum of original material did not change substantially over this period, nor was there much difference in postings of original material between online and on campus students. However, online students made many more postings in response to other students' postings than did on campus students
\end{abstract}

Key words: Online learning, computer mediated communication, student experiences.

\section{INTRODUCTION}

This paper will investigate the communication between teaching staff and students in one postgraduate subject that is taught in both online and on campus modes. Numerical and content analysis of email communication with the lecturer and postings to the subjects' electronic discussion forum investigate the question of whether, in this subject, computer mediated communication (CMC) changed over a two year period and whether CMC was used to discuss content material to enrich the quality of students' learning.

The original version of this chapter was revised: The copyright line was incorrect. This has been corrected. The Erratum to this chapter is available at DOI: 10.1007/978-0-387-35700-3_33 


\subsection{Computers and Curriculum}

The postgraduate subject Computers \& Curriculum is offered in both 'on campus' and 'online' mode (online from 1999). Studying on campus entails coming to class one evening a week and having access to all online materials (defined as 'adjunct mode' by Harasim, 2000), while those studying online are unlikely to visit the campus or meet the lecturer or other students in person ('totally online mode', Harasim, 2000). Enrolments are generally between 20 and 25 students. The proportion of the class studying online has increased annually since being offered online; from $29 \%$ in 1999 to $55 \%$ in 2002. Assessment tasks for students studying on campus or online are identical and the same lecturer teaches all students and marks all assessment tasks. Most students studying in online mode in 2002 had completed at least one previous subject online.

Students come from a wide range of teaching backgrounds and teach in primary schools (K-6), secondary schools (Years 7-12), or in adult education (including technical and further education, university, or professional associations). The wide range of ages that students in this subject teach (ages 5 to adult) means that material that is relevant to them professionally also covers a wide range. This diversity of interests is addressed by structuring the subject around twelve topics of relevance to educators of learners of all ages, with students focusing more deeply on four of these topics of their choice, and assessment tasks being focused on the age group and learning area of relevance to each student. This model is termed a 'Choose Your Own Adventure' style of subject-students decide which areas of the curriculum they will focus their efforts in, and assessment tasks are designed to be of significance and authentic in the student's professional setting. This negotiation of the focus of the subject and assessment tasks with each student gives students control of their learning and means that learning outcomes are relevant to the students' needs and their professional context.

Observations suggest that assessment tasks define, to a large extent, how students will engage with that subject. In this subject there are four assessment tasks (one with sub-tasks):

- Literature Review on a negotiated topic relevant to using computers in an educational setting and learning area relevant to the student.

- Seminar paper that draws together findings from the literature and relates findings to the professional context of the student.

- Evaluation of a piece of software/technology relevant to the learning area and educational setting of the student.

- Four 'Reflective Tasks' (focusing on four of the twelve subject topics). Students read notes on the topic and read more widely in the area and produce three statements about computers and the learning 
relating to this topic, with each statement supported by a single paragraph, with references to the literature and to their professional experiences. Students also suggest one additional reading in the topic area.

Assessment tasks are due at dates set throughout the semester to ensure that students engage with the subject early and remain engaged throughout the semester. Students submit work via email or on paper (the student's choice, with most online students submitting tasks via email). Students are also directed to post their seminar paper and four reflective tasks to the discussion forum. These tasks require that students engage with the current literature about computers and the curriculum and relate this to their own professional context. Relating readings to the student's professional context is a powerful way of engaging students in learning and increasing the relevance of their studies.

Observations and student feedback suggest that reflection and connecting the literature to the student's professional context works well in this subject. The question "Was this subject taught well?" scored 4.2 or more (on a 5point scale) on the University's annual 'Quality of Teaching' survey from 1999 to 2002 (average 4.5). Ongoing engagement of students and the subject's connection to students' professional lives is believed by the author to be important in this success.

\section{CLAIMS ABOUT CMC IN ONLINE EDUCATION}

Many claims have been made about the role that teacher-student and student-student communication can play in online learning and it is widely accepted that $\mathrm{CMC}$ can enrich the educational experiences of students (see, for example, Harasim, 2000, Langan, 1997, Leiblein, 2000). Mazoue (1999) considers that "the flexible, open ended availability of online course materials provides students with an expanded range of instructional opportunities for acquiring, exchanging, and meaningfully reflecting on the significance of information" (p104). This theme of CMC enriching online learning has been voiced by many and is seen as one key features that distinguish online learning from traditional distance education, where students work largely in isolation from their classmates. The potential capabilities of CMC to enrich learning is not disputed by the author, but observations of students in the subject Computers \& Curriculum suggested that, although useful for some students, CMC was not vital to support learning for all students.

In this subject email was not required between students and the lecturer but was, by far, the most convenient and the most widely used means of 
communication. Very little other forms of communication occurred between the lecturer and online students, and email was also the primary form of communication between the lecturer and on campus students between weekly classes. Students were directed to post a number of items to the subject's discussion forum, but it was not mandatory. The decision to not make this a mandatory requirement was to respect the privacy and intellectual property of students who did not wish to share their material with colleagues, this is similar to class discussions where students are encouraged, but not forced, to join discussions. Thus, use of CMC in this subject was not mandated, though it was strongly encouraged, and students made use of CMC with the lecturer and classmates as their own choice and as they saw value in using this as a resource for their learning.

This study seeks to investigate the use of CMC in a single subject to reveal any trends of students in this use of CMC by (i) comparing the number and nature of CMC by on campus and online students and (ii) the use of email and the subject's discussion forum by students in 2000 with 2002. Of particular interest was the use of CMC to discuss subject content material. It is acknowledged that this study is in a single subject and use of CMC by students in the subject may not be typical of use of CMC in all online subjects.

\section{METHODOLOGY}

Email communication from students in this subject to the lecturer and students' postings to the discussion forum for 2000 and 2002 were categorised and counted to investigate how CMC is being used to support online learning in this subject.

\subsection{Email from students to the lecturer}

To investigate the above questions emails from students to the lecturer ( 2000 \& 2002) were placed into the categories:

- Administrative matters (including submission of assessment tasks)

- Technical issues

- Discussion about the subject's content

When an email covered more than one topic, it was put into the category of the main part of the email. Emails in each category were tallied. 


\subsection{Students' postings to the discussion forum}

Students were directed (but not required) to post their four reflective pieces of writing and seminar paper to the subject's discussion forum. Students were encouraged to add comments to other students' reflections and were directed to question and comment on the seminar papers of other students and to respond to questions posed about their postings.

Postings to the discussion forum were placed into the categories:

- Original Content - where the student posted an item such as reflective tasks and the seminar paper and students' introductions of themselves to the group.

- Responding Content - where the student posted an item in response to another posting.

Postings were also categorized into:

- Introductory postings - where students introduced themselves to the group. Students were directed to introduce themselves to their colleagues.

- Subject content postings - where postings were about the content matter of the subject or were commenting or questioning on other students' postings about content matter.

Emails and postings in each of these categories were tallied and the median, maximum and minimum numbers in each category for 2000 and 2002 calculated.

\section{RESULTS AND DISCUSSION}

\subsection{Email between students and lecturer}

The median number of emails from on campus students to the lecturer increased from 2000 to 2002 (Table 1), while the median number of emails from online students dropped. Emails about administrative matters comprised the bulk of emails from all students in both 2000 and 2002. It should be noted that submission of assessment tasks was part of this category. Online students could submit assessment tasks by post, but most submitted them by email. Although on campus students attended weekly classes with the lecturer, some chose to submit assessment tasks by email. Many other of the emails about administrative matters were clarifying requirements or requesting extensions. The range in the number of emails varied widely, with one online student (2002) emailing 29 times about administrative matters. Online students, not surprisingly, emailed the 
lecturer about content matter more often than on campus students, who had the chance to talk with the lecturer during and after class.

Table 1 Median, minimum \& maximum numbers of emails from students to lecturer; by year and mode of study. [Note: Administration includes submission of tasks.]

\begin{tabular}{llccccccccc}
\hline Year & Mode & \multicolumn{3}{c}{ Administration } & \multicolumn{3}{c}{ Technical } & \multicolumn{3}{c}{ Content } \\
\cline { 2 - 11 } & & Med & Min & Max & Med & Min & Max & Med & Min & Max \\
2000 & On campus $(\mathrm{n}=15)$ & 3 & 0 & 8 & 0 & 0 & 4 & 1 & 0 & 4 \\
2000 & Online $(\mathrm{n}=8)$ & 8 & 6 & 13 & 1.5 & 1 & 4 & 3.5 & 2 & 14 \\
2002 & On campus $(\mathrm{n}=9)$ & 7 & 4 & 13 & 0 & 0 & 4 & 1 & 0 & 3 \\
2002 & Online $(\mathrm{n}=11)$ & 8 & 5 & 29 & 0.5 & 0 & 2 & 2.5 & 0 & 10 \\
\hline
\end{tabular}

\subsection{Communication using discussion forum}

The number of postings of original content to the discussion forum did not change substantially between 2000 and 2002, nor was there any large difference between online and on campus students (Figure 1). These postings of original material were introductions to the group or assessment tasks (reflective tasks or seminar paper) that students were directed to post to the discussion forum. Students did not initiate postings of their own volition and only posted content that they were directed to.

In 2000 there were no responses to introductory postings by either online or on campus students, but in 2002 online (but not on campus) students responded to introductory postings (Table 2). A number of online students in 2002 had previously studied subjects online together and used the subject's discussion forum to renew their acquaintance and catch up on news. This did not happen in 2000, perhaps because students in 2000 had not built up a camaraderie in a previous online subject.

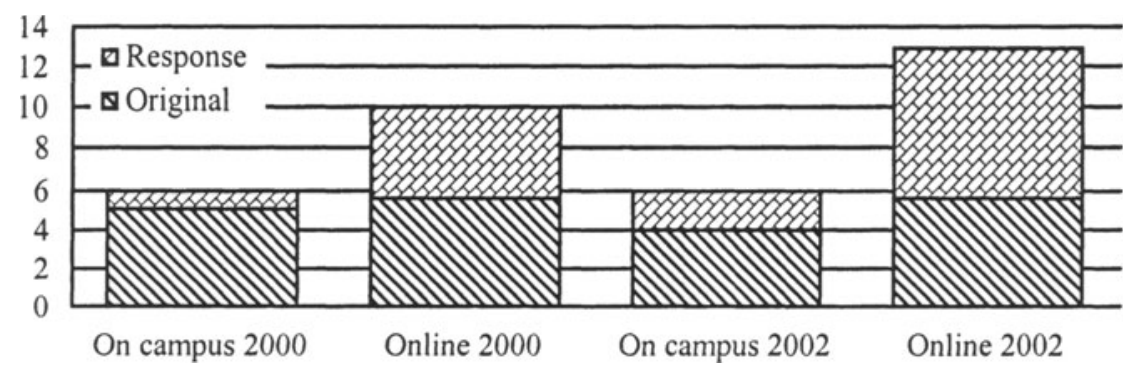

Figure 1 Median numbers of postings by students to the subject's discussion forum categorised as original content or responding to another student's posting.

The posting of original content related to the content matter of the subject (Table 3) was comprised entirely of assessment tasks that students 
were directed to post to the discussion forum to share with their classmates. It is interesting to note that some on campus students in both 2000 and 2002 chose not to post any materials to the discussion forum.

The median number of responses by online students to other postings about content matter did not change substantially from 2000 to 2002 (4.5 to $5)$, but the maximum number of postings of this type increased substantially (7 to 26). Some students, both online and on campus and in both 2000 and 2002 , did not engage in any discussion with colleagues on the subject's discussion forum.

Table 2 Median, minimum and maximum numbers of postings from students introducing themselves to the class; broken down by year and mode of study.

\begin{tabular}{llccccccc}
\hline & Mode of study & \multicolumn{3}{c}{$\begin{array}{c}\text { Posting of original } \\
\text { content }\end{array}$} & \multicolumn{3}{c}{$\begin{array}{c}\text { Responding to another } \\
\text { student's posting }\end{array}$} \\
\hline & & Median & Min & Max & Median & Min & Max \\
\hline 2000 & On campus $(\mathrm{n}=15)$ & 0 & 0 & 1 & 0 & 0 & 0 \\
2000 & Online $(\mathrm{n}=8)$ & 1 & 0 & 1 & 0 & 0 & 0 \\
2002 & On campus $(\mathrm{n}=9)$ & 0 & 1 & 1 & 0 & 0 & 0 \\
2002 & Online $(\mathrm{n}=11)$ & 1 & 0 & 1 & 3 & 0 & 6 \\
\hline
\end{tabular}

Table 3 Median, minimum and maximum numbers of postings from about content matter of the subject; broken down by year and by mode of study.

\begin{tabular}{llccccccc}
\hline & Mode of study & \multicolumn{3}{c}{$\begin{array}{c}\text { Posting of original } \\
\text { content }\end{array}$} & \multicolumn{3}{c}{$\begin{array}{c}\text { Responding to another } \\
\text { student's posting }\end{array}$} \\
\hline & & Median & Min & Max & Median & Min & Max \\
\hline 2000 & On campus $(\mathrm{n}=15)$ & 4 & 1 & 5 & 1 & 0 & 12 \\
2000 & Online $(\mathrm{n}=8)$ & 4 & 1 & 5 & 4.5 & 0 & 7 \\
2002 & On campus $(\mathrm{n}=9)$ & 4 & 0 & 5 & 2 & 0 & 8 \\
2002 & Online $(\mathrm{n}=11)$ & 5 & 2 & 5 & 5 & 0 & 26 \\
\hline
\end{tabular}

\section{CONCLUSIONS}

It is acknowledged that this single subject will not be representative of subjects taught in the online mode at either the author's university or at other institutions of higher education, however the results of this study are of interest as they shed light on students' use of CMCs where such use is not a requirement of the subject. Trends in this subject indicate that for both online and on campus students most email communication with the lecturer was related to administrative matters (including submission of assessment tasks) and that only a small proportion of email related to the content matter of the subject. There were more posting to the discussion forum by online students than on campus students in both 2000 and in 2002 and online 
students were more likely to post comments or question in response to postings by other students. For both online and on campus students all postings of original materials were assessment tasks that they had been directed to post-no student spontaneously posted a question, comment or statement about the content of the subject without prompting. [In 2003 this is not the case.]

These findings are interesting in the light of the claims of many educators about the potential of CMCs to enrich online education. For example, Harisim's (2000) claim that "Online interaction thus displayed fewer of the extremes typical of face-to-face class activity such as excessive or dominating input by a few and little or no participation by everyone else in the class" was not borne out in this class-some online students did not participate in the discussion forum at all, while one student made 26 postings. That some students chose not to participate in the discussion forum at all is also worthy of further investigation-did they make a conscious choice after having used discussion forums in other online subjects? Did they 'never get around to it'? Was it just 'too hard'? Do these students learn best on their own and do not require discussion to enrich their learning?

These questions are worthy of closer scrutiny as infrastructure is being developed for $\mathrm{CMC}$ to support online teaching and learning. Much is being written about the potential for CMCs to enhance the quality of online learning experiences, with the implicit assumption that all students will benefit, a closer look at the type of learner whose experience is enriched by these CMCs, and those for whom it is not valued, may be worthwhile focus of further studies.

\section{REFERENCES}

Harasim, L. (2000) Shift happens: Online education as a new paradigm in learning. Internet and Higher Education, $3: 41-61$.

Langan, T. (1997) Online education: a student's perspective. Campus Wide Information Systems 14 (4) : 128-132. MCB University Press.

Leiblein, E, (2000) Critical factors for successful delivery of online programs. Internet and Higher Education $3:$ 161-174.

Mazoue, J.G. (1999) The essentials of effective online instruction, Campus-Wide Information Systems $16(3): 104-110$.

Owston, R.D. (1997) "The World Wide Web: A technology to enhance teaching and learning?" Educational Researcher 26 (2): 27-33. 